\title{
Sex and onset-age-related features of excessive daytime sleepiness and night- time sleep in patients with Parkinson's disease
}

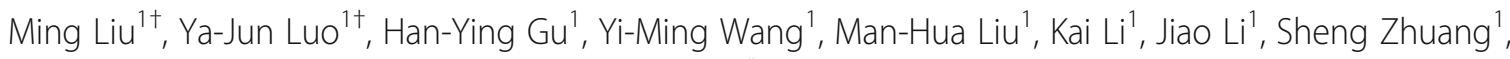
Yun Shen ${ }^{1}$, Hong Jin ${ }^{1}$, Jing Chen ${ }^{1}$, Cheng-Jie Mao ${ }^{1 *}$ and Chun-Feng Liu ${ }^{1,2}$

\begin{abstract}
Background: The clinical characteristics of Parkinson's disease (PD) differ between men and women, and late- and earlyonset patients, including motor symptoms and some nonmotor symptoms, such as cognition, anxiety, and depression.

Objective: To explore the features of excessive daytime sleepiness (EDS) and night-time sleep quality in PD patients of different sexes and age at onset (AAO).

Methods: Demographic data and clinical characteristics of 586 PD patients were collected. Epworth Sleepiness Scale (ESS) and Pittsburgh Sleep Quality Index (PSQI) were used to investigate the daytime drowsiness and nocturnal sleep. Multivariate logistic regression analysis was used to explore the risk factors of EDS and poor night-time sleep quality.

Results: Sleep disorders were common in PD patients. EDS was more prominent in men than in women. There was no significant difference in ESS scores between late-onset PD (LOPD) and early-onset PD. LOPD patients had a higher probability of poor night-time sleep quality. Male sex, disease duration, and depression were risk factors for EDS. In all patients of both sexes and all AAO, depression was a risk factor for poor night-time sleep.
\end{abstract}

Conclusion: More attention should be paid to sleep disorders of PD patients, especially male LOPD patients. Depression is a common risk factor for EDS and poor sleep quality in PD patients.

Keywords: Parkinson's disease, Sex difference, Age at onset, Excessive daytime sleepiness, Nocturnal sleep quality

\footnotetext{
*Correspondence: drchengjiemao@163.com

${ }^{+}$Ming Liu and Ya-Jun Luo contributed equally to this study.

Ming Liu and Ya-Jun Luo are share first authorship.

'Department of Neurology and Suzhou Clinical Research Center of

Neurological Diseases, the Second Affiliated Hospital of Soochow University,

Suzhou 215004, Jiangsu Province, China

Full list of author information is available at the end of the article
}

(c) The Author(s). 2021 Open Access This article is licensed under a Creative Commons Attribution 4.0 International License, which permits use, sharing, adaptation, distribution and reproduction in any medium or format, as long as you give appropriate credit to the original author(s) and the source, provide a link to the Creative Commons licence, and indicate if changes were made. The images or other third party material in this article are included in the article's Creative Commons licence, unless indicated otherwise in a credit line to the material. If material is not included in the article's Creative Commons licence and your intended use is not permitted by statutory regulation or exceeds the permitted use, you will need to obtain permission directly from the copyright holder. To view a copy of this licence, visit http://creativecommons.org/licenses/by/4.0/ The Creative Commons Public Domain Dedication waiver (http://creativecommons.org/publicdomain/zero/1.0/) applies to the data made available in this article, unless otherwise stated in a credit line to the data. 


\section{Introduction}

Parkinson's disease (PD) is the second most common neurodegenerative disease, characterized by major motor symptoms such as tremor, rigidity, bradykinesia, and postural instability. The motor manifestations of PD are related to the cortico-striatal pathway dysfunction caused by degeneration of dopaminergic neurons in the nigrostriatal pathway [1]. Various nonmotor symptoms (NMSs) reflect the dysfunction outside the nigrostriatal pathway, including neuropsychiatric, cognitive, gastrointestinal and sensory symptoms, as well as sleep disorders. There is increasing evidence that NMSs may appear before motor symptoms, which may negatively affect quality of life more than motor symptoms do [2].

Sleep disorders can affect up to $90 \%$ of PD patients [3]. The pathophysiology of sleep-wake disturbances in PD is largely unknown and may be caused by multiple factors, including the effects of motor symptoms and NMSs on sleep, adverse reactions to dopaminergic medication, and degeneration of central sleep regulatory areas [4]. The sleep-wake disorders in PD include insomnia, rapid eye movement (REM) sleep behavior disorder (RBD), excessive daytime sleepiness (EDS), restless leg syndrome (RLS), periodic limb movement (PLM), and sleep apnea syndrome (SAS). Among these, EDS and poor night-time sleep are the most common types of sleep disorders in PD patients. Sleep disorders can lead to emotional and cognitive impairment, decreased quality of life, and increased risk of accidents, leading to increased morbidity and mortality in this population $[5,6]$.

Although most PD patients are elderly and known as late-onset PD (LOPD) patients, $5-10 \%$ of patients develop symptoms before the age of 40 or 50 years. They are called early-onset PD (EOPD) patients. Studies have revealed that sex and age at onset (AAO) are important factors affecting the clinical phenotypes of PD, not only for motor symptoms but also for NMSs. The prevalence and incidence of PD in men are higher than in women [7]. Female patients may have a more benign phenotype in the early stage [8]. However, as the disease progresses, women seem to be at higher risk of treatment-related complications, such as motor and nonmotor fluctuations, dyskinesia, and high levels of disability $[9,10]$. In terms of NMSs, male patients may experience more cognitive impairment and urinary symptoms, but less emotional, apathy and pain symptoms [11, 12]. LOPD also shows more NMSs, such as cognitive dysfunction, autonomic dysfunction, and gastrointestinal symptoms [13, 14].

There are few studies on sleep disorders in patients with $\mathrm{PD}$ of different sexes and $\mathrm{AAO}$, and the results are controversial. It has been suggested that sleep disorders are more common in female PD patients, but a recent multicenter study found that the incidence of sleep disorders was similar in men and women [15]. Female patients are more likely to have symptoms such as difficulty falling asleep and RLS [16]. Male patients are more likely to have EDS and more aggressive behavior with RBD [4, 17, 18].

The purpose of this study was to investigate the clinical characteristics of EDS and night-time sleep quality of PD patients of different sexes and AAO by Epworth Sleepiness Scale (ESS) and Pittsburgh Sleep Quality Index (PSQI), and to explore the possible influencing factors.

\section{Materials and methods \\ Patients}

A total of 586 PD patients were enrolled in this study at the Second Affiliated Hospital of Soochow University from January 2014 to December 2019. Subjects were diagnosed with idiopathic PD according to the UK PD Society Brain Bank Clinical Diagnostic Criteria [19]. Patients who were able to complete a detailed evaluation were enrolled in this study. Subjects were excluded if they had a secondary parkinsonism syndrome, atypical parkinsonian syndrome, traumatic head or spine injury, malignant tumor, epilepsy, encephalitis, and global cognitive impairment (Mini-mental State Examination [MMSE] [20] score < 24). Patients are divided into EOPD (AAO $\leq 50$ years) and LOPD (AAO > 50 years). We collected demographic and clinical data in detail, including sex, age, AAO, disease duration, daily levodopa equivalent dose (LED), motor subtype, motor fluctuation, and dyskinesia. Motor function was assessed by the Unified Parkinson's Disease Rating Scale (UPDRS) Part III [21], and disease severity was evaluated according to the Hoehn and Yahr (H\&Y) Stage [22]. To categorize motor subtypes, we evaluated the UPDRS Part III, and adopted the classification scheme described by Schiess, MC. et al. [23], thereby obtaining the tremor/akinetic-rigid (T/AR) ratio. We used portions of the UPDRS III, and obtained a tremor score (sum of items 20-21 and history of arm tremor [two items] divided by 9 [total number of subitems]) and a non-tremor score (sum of items 18, 19, 22, 27-31 divided by 12 [total number of subitems]). Based on this method, AR subjects had a ratio $<0.8$, whereas tremor dominant (TD) subjects had a ratio $>1.0$, and mixed subjects had a ratio range from 0.8 to 1 . Hamilton Rating Scale for Depression (HRSD) was used to evaluate depression [24]. Screening of RBD was made according to RBD Screening Questionnaire (RBDSQ) [25].

\section{Sleep assessments}

Daytime sleepiness was evaluated by the Epworth Sleepiness Scale (ESS) [26], a generic scale recommended for measuring the risk of falling asleep during daily activities in the PD population [27]. As reported, ESS shows adequate coincidence with results of multiple sleep latency 
test (MSLT) and overnight polysomnography (PSG), as well as SCOPA-Sleep Daytime Sleepiness (SCOPA-Sleep-DS, a PD-specific scale) scores in PD patients [28]. It contains eight questions, each with a score ranging from 0 (would never doze) to 3 (high chance of dozing). A cut-off score $\geq$ 10 was used to define EDS. Pittsburgh Sleep Quality Index (PSQI) was used to evaluate night-time sleep quality of patients in the past month [29]. The scale was "recommended" for screening and measuring severity of overall sleep problems in PD patients [27]. The PSQI scale shows strong correlation with SCOPA-Sleep [28]. Although the PSQI does include five items to be filled out by the caregiver, but those are not included in the total score. Nineteen individual items generate seven component scores (subjective sleep quality, sleep latency, sleep duration, habitual sleep efficiency, sleep disturbances, use of sleeping medication, and daytime dysfunction). The total score ranges from 0 to 21 , and the higher the score, the worse the sleep quality. We distinguished between good and poor sleepers using a cut-off point $>5$ with good sensitivity and specificity.

\section{Statistics}

The participants were divided into male and female, and EOPD and LOPD patients. Continuous variables including age, AAO, level of education, duration of disease, Daily LED, H-Y stage, UPDRS I, UPDRS II, UPDRS III, HRSD and MMSE score were expressed as mean \pm standard deviation or median (interquartile range). Use the Student's $\mathrm{T}$ test for comparisons when the variables met the normal distribution, and Mann-Whitney $\mathrm{U}$ test for data that did not have a normal distribution. Categorical variables including motor subtype, motor fluctuation, dyskinesia, RBD, smoking, family history of PD, history of hypertension and diabetes mellitus, and use of drugs for PD were expressed as frequency (\%) and were compared using the $x^{2}$ test or Fisher's exact test. Multivariate logistic regression analysis was conducted to explore the risk factors of declined sleep quality and EDS in patients with PD according to sex and AAO stratifications. We included age, sex, AAO, disease duration, UPDRS I, UPDRS II, and UPDRS III score, motor subtype, daily LED, RBD, HRSD and MMSE in adjusted models. All $p$ values were two-tailed, and a significance level of 0.05 was used. Statistical analysis was conducted using SAS version 9.2 (Cary, NC, USA).

\section{Results}

\section{Demographic and clinical characteristics}

Among the 586 patients with PD, there were 347 males (59.2\%), 239 females (40.8\%), 86 EOPD (14.7\%) and 500 LOPD (85.3\%) patients. The demographic and clinical characteristics of patients with PD are listed in Table 1.
Most of our subjects had H\&Y staging $\leq 2.5$. In our study, 461 patients had H\&Y 2.5 or lower, 103 patients had H\&Y 3 , and only 17 and 5 patients had 4 and 5 points, respectively. Thus, our results may be more reflective of the characteristics of patients in the initial and medium stages. There was no significant sex difference in PD patients in terms of AAO, H\&Y stage, UPDRS I and II score, motor subtype, movement fluctuation, dyskinesia, family history of PD, concurrent disease, RBD, MMSE, depression score, dopamine drugs, and daily LED. The educational level [9.0 years $(6.0-12.0)$ vs. 9.0 years $(2.0-9.0), p<0.001]$, the number of smokers [120 (34.6\%) vs. $5(2.1 \%), p<0.001]$, the UPDRS III scores [24.0 (16.0-33.0) vs $22.0(12.0-$ $30.0), p=0.004$ ] were higher in men. There was no significant difference between EOPD and LOPD patients in terms of disease duration, H\&Y stage, UPDRS III score, movement fluctuation, dyskinesia, smoking, RBD, depression score, dopamine drugs, and daily LED. The AAO of LOPD patients was $63.9 \pm 7.4$ years. LOPD patients had higher UPDRS I scores $(p<0.001)$ and UPDRS II scores $(p=0.001)$. The number of LOPD patients with hypertension was $122 / 500(24.4 \%)$, which was significantly higher than that in EOPD patients $(12 / 86,14.0 \%)(p=0.033)$. This cohort seems to have more severe cognitive impairment $(p<0.001)$. The AAO of EOPD patients was $45.1 \pm$ 5.2 years, and more patients had a family history of PD than LOPD patients had $(11 / 86,12.8 \%$ vs $31 / 500,6.2 \%$, $p=0.029$ ). The classification of motor subtypes was different between the two groups $(p=0.023)$. Patients with EOPD tend to present with tremor-based motor symptoms $(22,25.6 \%$ vs $88,17.6 \%)$, while patients with LOPD are more likely to present with rigidity $(50,58.1 \%$ vs 363 , $72.6 \%)(p=0.033)$.

\section{Sleep evaluation}

The daytime sleepiness and night-time sleep quality of PD patients with different sexes and AAO are shown in Table 2. The ESS scores of male PD patients were significantly higher than those of female patients $(p<0.001)$. PD patients with ESS score $\geq 10$ accounted for $24.1 \%$, of which male patients $(102 / 347,29.4 \%)$ were more common than female patients $(39 / 239,16.3 \%)(p<0.001)$. There was no difference in ESS score between EOPD and LOPD patients. The PSQI scores were higher in LOPD patients $(p=0.006)$. PSQI $>5$ was found in $53.7 \%$ of PD patients, among whom, LOPD $(276 / 500,55.2 \%)$ was significantly more common than EOPD (35/86, 40.7\%) $(p<0.013)$. There was no difference in night-time sleep quality between male and female PD patients in the past month.

\section{Risk factors of ESS and PSQI in PD patients based on sex and AAO stratifications}

Multivariate logistic regression analysis showed that in all PD patients, the risk factors of ESS were male sex, 
Table 1 Baseline characteristics of 586 patients with Parkinson's disease

\begin{tabular}{|c|c|c|c|c|c|c|}
\hline Characteristic $^{a}$ & $\begin{array}{l}\text { Male } \\
(n=347)\end{array}$ & $\begin{array}{l}\text { Female } \\
(n=239)\end{array}$ & $P$-value & EOPD $(n=86)$ & LOPD $(n=500)$ & $P$-value \\
\hline Age, years & $65.7 \pm 10.2$ & $64.1 \pm 9.03$ & 0.049 & $49.5 \pm 6.8$ & $67.7 \pm 7.5$ & $<0.001$ \\
\hline Age at onset of $P D$, years & $61.5 \pm 10.2$ & $60.6 \pm 9.0$ & 0.294 & $45.1 \pm 5.2$ & $63.9 \pm 7.4$ & $<0.001$ \\
\hline Education, years & $9.0(6.0-12.0)$ & $9.0(2.0-9.0)$ & $<0.001$ & $9.0(6.0-12.0)$ & $9.0(6.0-12.0)$ & 0.030 \\
\hline Duration of disease, months & $36.0(22.0-72.0)$ & $36.0(16.0-60.0)$ & 0.047 & $41.0(17.8-84.0)$ & $36.0(18.0-63.8)$ & 0.433 \\
\hline Daily LED, mg/d & $300(0.0-400.0)$ & $200(0.0-400.0)$ & 0.480 & $225(0.0-450.0)$ & $250(0.0-400.0)$ & 0.773 \\
\hline Hoehn-Yahr stage & $2.0(1.5-2.5)$ & $2.0(1.5-2.5)$ & 0.109 & $2.0(1.5-2.5)$ & $2.0(1.5-2.5)$ & 0.249 \\
\hline UPDRS I & $3.0(2.0-5.0)$ & $3.0(2.0-4.0)$ & 0.790 & $3.0(1.0-4.0)$ & $3.0(2.0-5.0)$ & $<0.001$ \\
\hline UPDRS ॥ & $9.0(8.0-14.0)$ & $10.0(7.0-14.0)$ & 0.240 & $9.0(5.0-12.0)$ & $11.0(7.0-14.0)$ & 0.001 \\
\hline UPDRS III & $24.0(16.0-33.0)$ & $22.0(12.0-30.0)$ & 0.004 & $21.0(14.5-32.0)$ & $24.0(15.0-32.8)$ & 0.430 \\
\hline Motor subtype & & & 0.104 & & & 0.023 \\
\hline TD & $62(17.8)$ & $52(21.7)$ & & $22(25.6)$ & 88 (17.6) & \\
\hline$A-R$ & $252(72.8)$ & $161(67.3)$ & & $50(58.1)$ & $363(72.6)$ & \\
\hline$M X$ & $33(9.4)$ & $26(11)$ & & $14(16.3)$ & $49(9.8)$ & \\
\hline Motor fluctuation & $47(13.5)$ & $39(16.3)$ & 0.330 & $11(12.8)$ & $75(15.0)$ & 0.583 \\
\hline Dyskinesia & $14(4.0)$ & $15(6.3)$ & 0.219 & $4(4.7)$ & $25(5.0)$ & 0.890 \\
\hline Cigarette smoking & $120(34.6)$ & $5(2.1)$ & $<0.001$ & $23(26.7)$ & $102(20.4)$ & 0.185 \\
\hline Family history of PD & $25(7.2)$ & $17(7.1)$ & 0.966 & $11(12.8)$ & $31(6.2)$ & 0.029 \\
\hline History of hypertension & $82(23.6)$ & $52(21.8)$ & 0.596 & $12(14.0)$ & $122(24.4)$ & 0.033 \\
\hline History of diabetes mellitus & $24(6.9)$ & $14(5.9)$ & 0.609 & $3(3.5)$ & $35(7.0)$ & 0.222 \\
\hline Use of levodopa & $209(60.2)$ & $146(61.1)$ & 0.835 & $45(52.3)$ & $310(62.0)$ & 0.090 \\
\hline Use of dopamine agonists & $98(28.2)$ & $57(23.8)$ & 0.347 & $22(25.6)$ & $133(26.6)$ & 0.843 \\
\hline Use of MAOBI & $30(8.6)$ & $15(6.3)$ & 0.290 & $10(11.6)$ & $35(7.0)$ & 0.137 \\
\hline Use of amantadine & $51(14.7)$ & $31(13.0)$ & 0.554 & $15(17.4)$ & $67(13.4)$ & 0.318 \\
\hline Use of COMTI & $12(3.5)$ & $3(1.3)$ & 0.097 & $0(0.0)$ & $15(3.0)$ & 0.104 \\
\hline RBD & $126(36.2)$ & $72(30.0)$ & 0.110 & $24(27.9)$ & $173(34.2)$ & 0.253 \\
\hline HRSD & $7.0(3.0-13.0)$ & $7.0(3.0-15.0)$ & 0.446 & $7.0(2.0-13.0)$ & $7.0(3.0-14.0)$ & 0.682 \\
\hline MMSE & $28.0(26.0-29.0)$ & $27.0(26.0-29.0)$ & 0.055 & $29.0(27.0-30.0)$ & $28.0(26.0-29.0)$ & $<0.001$ \\
\hline
\end{tabular}

${ }^{a}$ Continuous variables are expressed as mean \pm standard deviation or as median (interquartile range). Categorical variables are expressed as frequency (percent) Abbreviations: PD Parkinson's disease, LED Levodopa-equivalent dose, UPDRS / Score of first part of Unified Parkinson Disease Rating Scale, UPDRS II Score of second part of Unified Parkinson Disease Rating Scale, UPDRS III Score of third part of Unified Parkinson Disease Rating Scale, TD Tremor Dominant, A-R Akineticrigid, MX Mixed, MAOBI Monoamine oxidase-B inhibitor, COMTI Catechol-O-methyltransferase inhibitor, RBD Rapid eye movement sleep behavior disorder, HRSD Hamilton Rating Scale for Depression, MMSE Mini-mental State Examination

Table 2 Sleep scales results for the sex stratification and age at onset stratification in PD patients

\begin{tabular}{|c|c|c|c|c|c|c|}
\hline Variables $^{a}$ & $\begin{array}{l}\text { Male } \\
n=347\end{array}$ & $\begin{array}{l}\text { Female } \\
n=239\end{array}$ & $P$-value & $\begin{array}{l}\text { EOG } \\
n=86\end{array}$ & $\begin{array}{l}\text { LOG } \\
n=500\end{array}$ & $P$-value \\
\hline ESS & $6.0(3.0-10.0)$ & $4.0(1.0-8.0)$ & $<0.001$ & $4.5(2.0-9.0)$ & $5.5(2.0-9.0)$ & 0.203 \\
\hline$E S S \geq 10, n \%$ & $102(29.4)$ & 39 (16.3) & $<0.001$ & $20(23.3)$ & $121(24.2)$ & 0.850 \\
\hline PSQI & $6.0(4.0-9.0)$ & $6.0(4.0-9.0)$ & 0.761 & $5.0(2.0-8.0)$ & $6.0(4.0-9.0)$ & 0.006 \\
\hline PSQI> 5, n\% & $182(52.4)$ & $129(54.0)$ & 0.716 & $35(40.7)$ & $276(55.2)$ & 0.013 \\
\hline
\end{tabular}

${ }^{a}$ Continuous variables are expressed as mean \pm standard deviation or as median (interquartile range). Categorical variables are expressed as frequency (percent) Abbreviations: EOG Early-onset group, LOG Late-onset group, ESS Epworth Sleepiness Scale, PSQI Pittsburgh Sleep Quality Index 
disease duration, and HRSD score. According to sex stratification, HRSD score and AAO were risk factors for ESS in male and female PD patients, respectively. According to AAO stratification, HRSD score was the only risk factor for ESS in EOPD patients, while in LOPD patients, male sex, disease duration, and HRSD score were risk factors (Table 3 ). In all patients with different sexes and AAO, HRSD score was the common risk factor related to PSQI (Table 4).

\section{Discussion}

Our study focused on analyzing the clinical characteristics of daytime sleepiness and night-time sleep quality in PD patients of different sexes and AAO.

PD patients with different sexes and AAO show certain specific clinical phenotypes [10, 14, 30]. Similar findings were found in our study. The prevalence of PD in male patients is 1.45 times higher than that of female patients. Male patients had more severe motor symptoms. This benign phenotype of female may be related to differences in sex hormones. Some studies have revealed that estrogen has a neuroprotective effect on the dopaminergic system, thus reducing the risk of PD and the rate of disease progression in women [31]. Sex differences in genes are also involved in different clinical characteristics. The low expression of some GABA receptor genes observed in women may be related to the prevalence of tremor as the first symptom and the increased expression of proinflammatory genes detected in women may explain that they are more likely to be

Table 3 Significant predictors of ESS as binary variables according to sex stratification and age at onset stratification from multivariate logistic regression analysis in PD patients

\begin{tabular}{lll}
\hline Variables & Odds ratio (95\% confidence interval) & $P$-value \\
\hline Overall model & & \\
Male sex & $2.163(1.398-3.346)$ & 0.001 \\
Disease duration & $1.010(1.001-1.018)$ & 0.023 \\
HRSD & $1.040(1.016-1.065)$ & 0.001 \\
Male model & & 0.002 \\
$\quad$ HRSD & $1.047(1.047-1.017)$ & \\
Female model & & 0.046 \\
$\quad$ Age at onset & $1.196(1.003-1.425)$ & \\
EOG model & & 0.051 \\
$\quad$ HRSD & $1.060(1.000-1.125)$ & $<0.001$ \\
LOG model & & 0.017 \\
Male sex & $2.362(1.465-3.808)$ & 0.006 \\
\hline Disease duration & $1.011(1.002-1.020)$ & \\
HRSD & $1.038(1.011-1.067)$ &
\end{tabular}

Abbreviations: ESS Epworth Sleepiness Scale, PD Parkinson's disease, HRSD Hamilton Rating Scale for Depression, EOG Early onset group, LOG Late-onset group
Table 4 Significant predictors of PSQI as binary variables according to sex stratification and age at onset stratification from multivariate logistic regression analysis in PD patients

\begin{tabular}{lll}
\hline Variables & Odds ratio (95\% confidence interval) & $P$-value \\
\hline $\begin{array}{lll}\text { Overall model } \\
\quad \text { HRSD }\end{array}$ & $1.098(1.069-1.128)$ & $<0.001$ \\
$\begin{array}{l}\text { Male model } \\
\quad \text { HRSD }\end{array}$ & $1.104(1.063-1.146)$ & $<0.001$ \\
$\begin{array}{l}\text { Female model } \\
\quad \text { HRSD }\end{array}$ & $1.103(1.056-1.153)$ & $<0.001$ \\
EOG model & & \\
$\quad$ HRSD & $1.084(1.021-1.151)$ & 0.008 \\
LOG model & & \\
HRSD & $1.111(1.007-1.146)$ & $<0.001$ \\
\hline
\end{tabular}

Abbreviations: PSQI Pittsburgh Sleep Quality Index, PD Parkinson's disease, HRSD Hamilton Rating Scale for Depression, EOG Early onset group, LOG Late-onset group

affected by depression and anxiety [32], although no differences in HRSD scores were found between men and women in our study. We found that women had worse cognitive function than men, although there was no statistical significance. Women have lower levels of education than men, which may explain the difference. A recent study on the relationship between occupational stress and PD risk shows that high job requirements seem to increase the risk of PD in men, especially among highly educated men [33], which may partly explain men's susceptibility to PD.

Age is the most important risk factor for PD. We found that patients with LOPD had higher UPDRS I and II scores, had relatively poor cognitive function and were more likely to present with the AR subtype. This is consistent with previous researches, suggesting that patients with LOPD show more axial symptoms, including abnormal posture and gait, as well as NMSs $[13,34]$. In contrast, the disease progresses slowly in EOPD, usually with family history and earlier motor complications [35]. About 19\% of EOPD patients in our study had a family history. A study based on autopsy of PD patients showed that EOPD patients have a higher proportion of lifelong use of amantadine and dopamine agonists and a higher incidence of dyskinesia [36]. However, there was no difference in dopaminergic drugs and motor complications between the two groups in our study, which may be related to the different samples and drug selection habits of doctors in different countries and regions.

Sleep disturbance is one of the most important NMSs that affect the quality of life in PD patients. Sleep deterioration is an important marker of the prodromal phase of PD. Some studies have shown that PD patients may have difficulty falling asleep, broken sleep, early awakening, lack 
of sleep, EDS, snoring, nightmares, and hallucinations. EDS in PD patients is associated with unexpected, sudden sleep or sleep seizures, which can increase driving risk and reduce quality of life [37]. EDS is also a marker of dopamine loss, and a lower [123I] FP-CIT (DaTscan) value in the caudate nucleus is associated with a higher EDS score [38]. In our study, $24.1 \%$ of PD patients reported EDS, and men had more and severer daytime sleepiness than women had. Multivariate logistic regression analysis showed that male sex, disease duration, and depression were associated with EDS in all PD patients and LOPD patients in particular; depression was associated with EDS in men and EOPD patients; and AAO was associated with EDS in female patients. Previous studies have shown that predictive factors for EDS include male sex, disease duration and severity of PD, dose of dopamine agonist, apnea or hypopnea index, and BMI $[39,40]$, which are similar to those in our study. NMSs such as depression, fatigue, pain, cognitive impairment, cardiovascular disease, urinary tract disorders, and thermoregulatory disorders may also lead to EDS [41]. A longitudinal study also showed that PSG parameters in EDS are more common in individuals with depression [42]. In PD patients, serotonergic, noradrenergic and cholinergic neurons in the brainstem also act as arousal systems to maintain awake, and dysfunction of these neurons in PD patients with depression can lead to EDS [43]. In terms of AAO, Guo et al. reported that the prevalence of EDS or fatigue in LOPD patients was higher than in EOPD patients [16]. However, we found no difference in the frequency and severity of EDS between LOPD and EOPD patients, which is the same as a previous longitudinal study [41]. We found that the AAO is a risk factor for EDS in female patients. In EOPD patients, EDS was associated with depression only but neither sex nor disease duration.

Besides experiencing EDS, PD patients may have other nocturnal sleep disorders. In our study, 53.7\% of PD patients had poor night-time sleep quality. It is generally believed that older women have lower subjective sleep quality than older men have, although PSG results showed a better sleep structure [44]. No difference was found between men and women in our study. Based on AAO stratification, the overall sleep quality of patients with LOPD was worse than that of EOPD patients, which is similar to the results of Mahale et al. [45]. Sleep disorders may increase with aging. Sleep efficiency began to decrease significantly after the age of 60 years, and the age-related sex difference was more significant in elderly patients [46]. We found that LOPD patients had higher UPDRS I and II scores, indicating that LOPD patients had more mental, behavioral and emotional problems such as depression, hallucinations, and decreased daily activity, and more NMSs that may be closely related to sleep quality. Multivariate logistic regression analysis showed that depression was the common risk factor for poor night-time sleep quality in all PD patients in our study, regardless of sex or early or late onset of PD. Around $30-40 \%$ of PD patients may experience depression [47]. In PD patients with depression, REM latency decreases, total REM sleep time and REM density increase, and slow-wave sleep decreased [48], which was closely related to nocturnal sleep, especially insomnia. It is suggested that the sleep disorders in PD patients are not only the results of dopamine deficiency and neurodegeneration of ascending awakening system, but also the results of damage to the serotoninergic and noradrenergic systems related to pain and depression [49]. However, the HRSD scale contains three sleep items. It may affect the scores of the PSQI and ESS, the effect of depression on sleep needs to be elucidated in more objective ways.

Our study had several limitations. Firstly, a healthy control group was not included. Secondly, most of our subjects had H\&Y 2.5 or less, reflecting the selection bias of our study. Our results may be more reflective of the characteristics of patients in the initial and medium stages. Thirdly, this study was conducted using rating scales, without PSG or MSLT. As a self-rated scale, the ESS scale does not include information from a caregiver or partner. Thus, the risk may be underestimated. The PSQI does not adequately cover other sleep disturbances such as RLS, RBD or PLMs. While the PSQI scale shows strong correlation with SCOPA-Sleep, but not with PSG. So further studies that combine the PD-specific questionnaire and PSG to evaluate the sleep disorders more comprehensively are needed.

\section{Conclusion}

In summary, our study shows that EDS and poor nighttime sleep quality are more common in PD patients. Male patients are more likely to have EDS than female patients have, and LOPD patients have worse night-time sleep quality. Male sex, disease duration, and depression are the main risk factors for EDS in PD patients, while depression is a predictive factor of poor night-time sleep quality in all PD patients, whether they are male or female, and have early- or late-onset PD. Clinicians should pay attention to sleep disorders of PD patients, especially in male and LOPD patients. Depression should be routinely evaluated in PD patients with sleep disorders.

\section{Abbreviations}

AAO: Age at onset; EDS: Excessive daytime sleepiness; EOPD: Early-onset Parkinson's disease; ESS: Epworth Sleepiness Scale; HRSD: Hamilton Rating Scale; LED: Levodopa equivalent dose; MMSE: Mini-mental State Examination; NMS: Nonmotor symptom; PD: Parkinson's disease; PSQI: Pittsburgh Sleep Quality Index; RBD: Rapid eye movement sleep behavior disorder; REM: Rapid eye movement; RLS: Restless leg syndrome; UPDRS: Unified Parkinson's

Disease Rating Scale 


\section{Acknowledgements}

We thank the study participants and their relatives, and the clinical staff for their support and contribution to this study.

\section{Authors' contributions}

Ming Liu and Ya-Jun Luo collected the data, analyzed the data, and drafted the manuscript. Han-Ying Gu, Yi-Ming Wang, Man-Hua Liu, Kai Li, Jiao Li, Sheng Zhuang, Yun Shen, Hong Jin, and Jing Chen collected the data. Cheng-Jie Mao and Chun-Feng Liu designed the study and analyzed the data. The author(s) read and approved the final manuscript.

\section{Funding}

This work was supported by the National Natural Science Foundation of China (grant number 81801258); Priority Academic Program Development of Jiangsu Higher Education Institutions (PAPD); Gusu Health Talents Training Project (GSWS2019041); Discipline Construction Program of the Second Affiliated Hospital of Soochow University (XKTJ-XK202001, XKTJ-RC202004); Jiangsu Provincial Key R\&D Program (grant number BE2018658); Jiangsu Provincial Medical Key Discipline Project (grant number ZDXKB2016022); Suzhou Clinical Research Center of Neurological Disease (grant number Szzx201503)

\section{Availability of data and materials}

All data generated or analyzed during this study are included in this published article. Some or all data or models generated or used during the study are available from the corresponding author by request.

\section{Declarations}

\section{Ethics approval and consent to participate}

We obey the principles of the 1983 Declaration of Helsinki and this study was approved by the Ethics Committee of the Second Affiliated Hospital of Soochow University. Informed consent was obtained from all participants. All methods were performed in accordance with the relevant guidelines and regulations.

\section{Consent for publication}

Not applicable.

\section{Competing interests}

The authors declare that they have no conflict of interest.

\section{Author details}

'Department of Neurology and Suzhou Clinical Research Center of Neurological Diseases, the Second Affiliated Hospital of Soochow University, Suzhou 215004, Jiangsu Province, China. ${ }^{2}$ Department of Neurology, Suqian First Hospital, Suqian, China.

\section{Received: 1 February 2021 Accepted: 7 April 2021}

\section{Published online: 19 April 2021}

\section{References}

1. Hou Y, Yang J, Luo C, Ou R, Song W, Liu W, et al. Patterns of striatal functional connectivity differ in early and late onset Parkinson's disease. J Neurol. 2016;263(10):1993-2003. https://doi.org/10.1007/s00415-016-8211-3.

2. Prakash KM, Nadkarni NV, Lye WK, Yong MH, Tan EK. The impact of nonmotor symptoms on the quality of life of Parkinson's disease patients: a longitudinal study. Eur J Neurol. 2016;23(5):854-60. https://doi.org/10.1111/ ene.12950.

3. Chahine LM, Amara AW, Videnovic A. A systematic review of the literature on disorders of sleep and wakefulness in Parkinson's disease from 2005 to 2015. Sleep Med Rev. 2017;35:33-50. https://doi.org/10.101 6/j.smrv.2016.08.001

4. Zhu K, van Hilten JJ, Marinus J. Course and risk factors for excessive daytime sleepiness in Parkinson's disease. Parkinsonism Relat Disord. 2016;24:34-40. https://doi.org/10.1016/j.parkreldis.2016.01.020

5. Bargiotas $P$, Ntafouli M, Lachenmayer ML, Krack P, Schüpbach WMM, Bassetti CLA. Apathy in Parkinson's disease with REM sleep behavior disorder. J Neurol Sci. 2019;399:194-8. https://doi.org/10.1016/j.jns.2019.02.028.
6. Bohnen $\mathrm{NI}$, Hu MTM. Sleep disturbance as potential risk and progression factor for Parkinson's disease. J Parkinsons Dis. 2019:9(3):603-14. https://doi. org/10.3233/JPD-191627.

7. Lubomski M, Louise Rushworth R, Lee W, Bertram KL, Williams DR. Sex differences in Parkinson's disease. J Clin Neurosci. 2014;21(9):1503-6. https:// doi.org/10.1016/j.jocn.2013.12.016.

8. Picillo M, Nicoletti A, Fetoni V, Garavaglia B, Barone P, Pellecchia MT. The relevance of gender in Parkinson's disease: a review. J Neurol. 2017;264(8): 1583-607. https://doi.org/10.1007/s00415-016-8384-9.

9. Bjornestad A, Forsaa EB, Pedersen KF, Tysnes O-B, Larsen JP, Alves G. Risk and course of motor complications in a population-based incident Parkinson's disease cohort. Parkinsonism Relat Disord. 2016;22:48-53. https:// doi.org/10.1016/j.parkreldis.2015.11.007.

10. Picillo M, Palladino R, Moccia M, Erro R, Amboni M, Vitale C, et al. Gender and non motor fluctuations in Parkinson's disease: a prospective study. Parkinsonism Relat Disord. 2016;27:89-92. https://doi.org/10.1016/j.parkreldis.2016.04.001.

11. Reekes $\mathrm{TH}$, Higginson $\mathrm{Cl}$, Ledbetter CR, Sathivadivel N, Zweig RM, Disbrow EA. Sex specific cognitive differences in Parkinson disease. NPJ Parkinsons Dis. 2020;6(1):7. https://doi.org/10.1038/s41531-020-0109-1.

12. Georgiev D, Hamberg K, Hariz M, Forsgren L, Hariz GM. Gender differences in Parkinson's disease: a clinical perspective. Acta Neurol Scand. 2017:136(6): 570-84. https://doi.org/10.1111/ane.12796.

13. Hu T, Ou R, Liu H, Hou Y, Wei Q, Song W, et al. Gender and onset age related-differences of non-motor symptoms and quality of life in drug-naive Parkinson's disease. Clin Neurol Neurosurg. 2018;175:124-9. https://doi.org/1 0.1016/j.clineuro.2018.11.001

14. Mendonca MD, Lampreia T, Miguel R, Caetano A, Barbosa R, Bugalho P. Motor and non-motor symptoms in old-age onset Parkinson's disease patients. J Neural Transm (Vienna). 2017;124(7):863-7. https://doi.org/10.1 007/s00702-017-1711-1.

15. Nicoletti A, Vasta R, Mostile G, Nicoletti G, Arabia G, lliceto G, et al. Gender effect on non-motor symptoms in Parkinson's disease: are men more at risk? Parkinsonism Relat Disord. 2017;35:69-74. https://doi.org/10.1016/j.pa rkreldis.2016.12.008.

16. Guo X, Song W, Chen K, Chen X, Zheng Z, Cao B, et al. Gender and onset age-related features of non-motor symptoms of patients with Parkinson's disease--a study from Southwest China. Parkinsonism Relat Disord. 2013; 19(11):961-5. https://doi.org/10.1016/j.parkreldis.2013.06.009.

17. Yao C, Fereshtehnejad S-M, Keezer MR, Wolfson C, Pelletier A, Postuma RB Risk factors for possible REM sleep behavior disorder: a CLSA populationbased cohort study. Neurology. 2018;92(5):475-85. https://doi.org/10.1212/ WNL.0000000000006849.

18. Gan-Or Z, Rao T, Leveille E, Degroot C, Chouinard S, Cicchetti F, et al. The Quebec Parkinson network: a researcher-patient matching platform and multimodal biorepository. J Parkinsons Dis. 2020;10(1):301-13. https://doi. org/10.3233/JPD-191775.

19. Gelb DJ, Oliver E, Gilman S. Diagnostic criteria for Parkinson disease. Arch Neurol. 1999;56(1):33-9. https://doi.org/10.1001/archneur.56.1.33.

20. Folstein MF, Folstein SE, McHugh PR. "mini-mental state". A practical method for grading the cognitive state of patients for the clinician. J Psychiatr Res. 1975;12(3):189-98. https://doi.org/10.1016/0022-3956(75)90026-6.

21. Goetz CG, Tilley BC, Shaftman SR, Stebbins GT, Fahn S, Martinez-Martin P, et al. Movement Disorder Society-sponsored revision of the unified Parkinson's disease rating scale (MDS-UPDRS): scale presentation and clinimetric testing results. Movement Disord. 2008;23(15):2129-70. https:// doi.org/10.1002/mds.22340.

22. Hoehn MM, Yahr MD. Parkinsonism: onset, progression and mortality. Neurology. 1967;17(5):427-42. https://doi.org/10.1212/WNL.17.5.427.

23. Schiess MC, Zheng H, Soukup VM, Bonnen JG, Nauta HJ. Parkinson's disease subtypes: clinical classification and ventricular cerebrospinal fluid analysis. Parkinsonism Relat Disord. 2000;6(2):69-76. https://doi.org/10.1016/S13538020(99)00051-6.

24. Hamilton M. A rating scale for depression. J Neurol Neurosurg Psychiatry. 1960;23(1):56-62. https://doi.org/10.1136/jnnp.23.1.56.

25. Stiasny-Kolster K, Mayer G, Schäfer S, Möller JC, Heinzel-Gutenbrunner M, Oertel WH. The REM sleep behavior disorder screening questionnaire--a new diagnostic instrument. Mov Disord. 2007;22(16):2386-93. https://doi. org/10.1002/mds.21740.

26. Johns MW. A new method for measuring daytime sleepiness: the Epworth sleepiness scale. Sleep. 1991;14(6):540-5. https://doi.org/10.1 093/sleep/14.6.540. 
27. Högl B, Arnulf I, Comella C, Ferreira J, Iranzo A, Tilley B, et al. Scales to assess sleep impairment in Parkinson's disease: critique and recommendations. Mov Disord. 2010;25(16):2704-16. https://doi.org/10.1002/mds.23190.

28. Kurtis MM, Balestrino R, Rodriguez-Blazquez C, Forjaz MJ, Martinez-Martin P. A review of scales to evaluate sleep disturbances in movement disorders. Front Neurol. 2018;9:369. https://doi.org/10.3389/fneur.2018.00369.

29. Buysse DJ, Reynolds CF, Monk TH, Berman SR, Kupfer DJ. The Pittsburgh sleep quality index: a new instrument for psychiatric practice and research. Psychiatry Res. 1989;28(2):193-213. https://doi.org/10.1016/0165-1781 (89)90047-4.

30. Iwaki H, Blauwendraat C, Leonard HL, Makarious MB, Kim JJ, Liu G, et al. Differences in the presentation and progression of Parkinson's disease by sex. Mov Disord. 2021;36(1):106-17. https://doi.org/10.1002/mds.28312.

31. Lee YH, Cha J, Chung SJ, Yoo HS, Sohn YH, Ye BS, et al. Beneficial effect of estrogen on nigrostriatal dopaminergic neurons in drug-naive postmenopausal Parkinson's disease. Sci Rep. 2019;9(1):10531. https://doi org/10.1038/s41598-019-47026-6.

32. Mariani E, Lombardini L, Facchin F, Pizzetti F, Frabetti F, Tarozzi A, et al. Sexspecific Transcriptome differences in Substantia Nigra tissue: a meta-analysis of Parkinson's disease data. Genes (Basel). 2018;9(6):275. https://doi.org/10.33 90/genes9060275.

33. Sieurin J, Andel R, Tillander A, Valdes EG, Pedersen NL, Wirdefeldt K. Occupational stress and risk for Parkinson's disease: a nationwide cohort study. Mov Disord. 2018;33(9):1456-64. https://doi.org/10.1002/mds.27439.

34. Pagano G, Ferrara N, Brooks DJ, Pavese N. Age at onset and Parkinson disease phenotype. Neurology. 2016;86(15):1400-7. https://doi.org/10.1212/ WNL.0000000000002461

35. Kelly MJ, Lawton MA, Baig F, Ruffmann C, Barber TR, Lo C, et al Predictors of motor complications in early Parkinson's disease: a prospective cohort study. Movement Disord. 2019;34(8):1174-83. https:// doi.org/10.1002/mds.27783.

36. Ferguson LW, Rajput AH, Rajput A. Early-onset vs. late-onset Parkinson's disease: a clinical-pathological study. Can J Neurol Sci. 2016;43(1):113-9. https://doi.org/10.1017/cjn.2015.244

37. Yoo SW, Kim JS, Oh YS, Ryu DW, Lee KS. Excessive daytime sleepiness and its impact on quality of life in de novo Parkinson's disease. Neurol Sci. 2019; 40(6):1151-6. https://doi.org/10.1007/s10072-019-03785-8.

38. Yousaf T, Pagano G, Niccolini F, Politis M. Excessive daytime sleepiness may be associated with caudate denervation in Parkinson disease. J Neurol Sci. 2018;387:220-7. https://doi.org/10.1016/j.jns.2018.02.032.

39. Tholfsen LK, Larsen JP, Schulz J, Tysnes O-B, Gjerstad MD. Development of excessive daytime sleepiness in early Parkinson disease. Neurology. 2015; 85(2):162-8. https://doi.org/10.1212/WNL.0000000000001737.

40. Phattanarudee S, Sangthong S, Bhidayasiri R. Association between sleep disturbances and daytime somnolence in Parkinson's disease. Eur Neurol. 2018;80(5-6):268-76. https://doi.org/10.1159/000496937.

41. Amara AW, Chahine LM, Caspell-Garcia C, Long JD, Coffey C, Hogl B, et al. Longitudinal assessment of excessive daytime sleepiness in early Parkinson's disease. J Neurol Neurosurg Psychiatry. 2017;88(8):653-62. https://doi.org/1 0.1136/jnnp-2016-315023.

42. Fernandez-Mendoza J, Vgontzas AN, Kritikou I, Calhoun SL, Liao D, Bixler EO. Natural history of excessive daytime sleepiness: role of obesity, weight loss, depression, and sleep propensity. Sleep. 2015;38(3):351-60. https://doi.org/1 $0.5665 /$ sleep.4488

43. Suzuki K, Miyamoto M, Miyamoto T, Iwanami M, Hirata K. Sleep disturbances associated with Parkinson's disease. Parkinsons Dis. 2011;2011:219056. https://doi.org/10.4061/2011/219056.

44. Åkerstedt T, Schwarz J, Gruber G, Lindberg E, Theorell-Haglöw J. The relation between polysomnography and subjective sleep and its dependence on age - poor sleep may become good sleep. J Sleep Res. 2016;25(5):565-70. https://doi.org/10.1111/jsr.12407.

45. Mahale R, Yadav R, Pal PK. Quality of sleep in young onset Parkinson's disease: any difference from older onset Parkinson's disease. Parkinsonism Relat Disord. 2015;21(5):461-4. https://doi.org/10.1016/j.pa rkreldis.2015.02.007

46. Mander BA, Winer JR, Walker MP. Sleep and human aging. Neuron. 2017; 94(1):19-36. https://doi.org/10.1016/j.neuron.2017.02.004.

47. Goodarzi Z, Mrklas KJ, Roberts DJ, Jette N, Pringsheim T, Holroyd-Leduc J. Detecting depression in Parkinson disease: a systematic review and metaanalysis. Neurology. 2016;87(4):426-37. https://doi.org/10.1212/WNL. 0000000000002898.
48. Wang YQ, Li R, Zhang MQ, Zhang Z, Qu WM, Huang ZL. The neurobiological mechanisms and treatments of REM sleep disturbances in depression. Curr Neuropharmacol. 2015;13(4):543-53. https://doi.org/10.21 74/1570159X13666150310002540.

49. French IT, Muthusamy KA. A review of sleep and its disorders in patients with Parkinson's disease in relation to various brain structures. Front Aging Neurosci. 2016;8:114. https://doi.org/10.3389/fnagi.2016.00114.

\section{Publisher's Note}

Springer Nature remains neutral with regard to jurisdictional claims in published maps and institutional affiliations.
Ready to submit your research? Choose BMC and benefit from:

- fast, convenient online submission

- thorough peer review by experienced researchers in your field

- rapid publication on acceptance

- support for research data, including large and complex data types

- gold Open Access which fosters wider collaboration and increased citations

- maximum visibility for your research: over $100 \mathrm{M}$ website views per year

At BMC, research is always in progress.

Learn more biomedcentral.com/submissions 